\title{
Subglottic Cancer cM1 TNM Finding v7
}

National Cancer Institute

\section{Source}

National Cancer Institute. Subglottic Cancer cM1 TNM Finding v7. NCI Thesaurus. Code C89090.

Subglottic cancer with distant metastasis. (from AJCC 7th Ed.) 